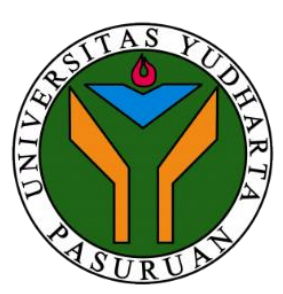

Halaman jurnal: http://jurnal.yudharta.ac.id/v2/index.php/EXPLORE-IT/

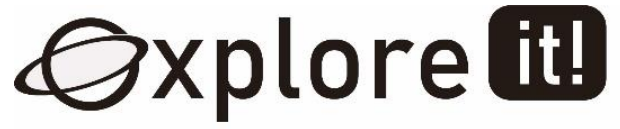

JURNAL KEILMUAN DAN APLIKASI TEKNIK INFORMATIKA

Akreditasi Sinta 5 (S5) - SK No. 36/E/KPT/2019

p-ISSN 2086-3489 (Print)- e-ISSN 2549-354X (Online) DOI https://doi.org/10.35891/explorit

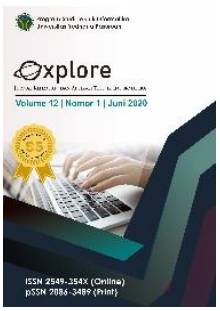

\title{
Sistem Monitoring Kualitas Udara dengan Platform Web
}

\author{
Medina Nadila Prima Putri ${ }^{1}$, Ade Silvia Handayani ${ }^{2}$, Martinus Mujur Rose ${ }^{3}$ \\ Teknik Elektro, Teknik Telekomunikasi, Politeknik Negeri Sriwijaya, Kota Palembang, Indonesia \\ email: ${ }^{1}$ medina.nadila@yahoo.com, ${ }^{2}$ ade_silvia@polsri.co.id, ${ }^{3}$ mujurrose@yahoo.com
}

\begin{tabular}{l}
\hline INFO ARTIKEL \\
\hline Sejarah Artikel: \\
Diterima 28 Agustus 2020 \\
Direvisi - \\
Disetujui 07 September 2020 \\
Dipublikasi 02 Desember 2020 \\
\hline Katakunci: \\
Monitoring \\
Website \\
Database \\
Wireless Sensor Network
\end{tabular}

\begin{abstract}
ABSTRAK
Pencemaran udara merupakan suatu masalah yang berdampak buruk bagi kehidupan makhluk hidup, terutama di kota-kota besar dan industri yang semakin hari semakin meningkat pencemaran udaranya. Media dan teknik penyampaian kualitas udara yang kurang informatif menjadi pemicu rendahnya kesadaran masyarakat terhadap kondisi lingkungan yang berdampak terhadap kualitas udara, oleh karena itu diperlukan sistem monitoring kualitas udara. Pada penelitian ini dirancang sebuah web yang berfungsi untuk monitoring serta sebagai media informasi untuk mengetahui kualitas udara, web monitoring tersebut akan digabungkan dengan Wireless Sensor Network sebagai alat perangakat keras (hardware) yang akan membaca dan mengambil data dari node-node sensor yang ada pada hardware wsn tersebut. Penelitian ini diharapkan dapat membantu masyarakat mengetahui kualitas udara pada lingkungan sekitar, sehingga bisa melakukan pencegahan dini terhadap kualitas udara yang tidak baik, karena apabila kualitas udara tidak baik maka akan berdampak buruk pada kesehatan masyarakat itu sendiri.
\end{abstract}

Keyword:

Monitoring

Website

Database

Wireless Sensor Network

DOI Artikel:

10.35891/explorit.v12i2.2262

\section{ABSTRACT}

Air pollution is a problem that has a bad impact on the lives of living things, especially in big cities and industries, which are increasingly air pollution. Uninformative media and air quality delivery techniques trigger low public awareness of environmental conditions that impact air quality, therefore an air quality monitoring system is needed. In this study, a web that functions for monitoring as well as information media to determine air quality is designed, the web monitoring will be combined with the Wireless Sensor Network as a hardware device that will read and retrieve data from sensor nodes on the hardware. wsn. This research is expected to be able to help the community know the air quality in the surrounding environment, so that they can take early prevention against bad air quality, because if the air quality is not good it will have a negative impact on public health. @2020 diterbitkan oleh Prodi Teknik Informatika Universitas Yudharta Pasuruan

\section{Pendahuluan}

Pencemaran udara merupakan suatu masalah yang berdampak buruk bagi kehidupan makhluk hidup. Dampak perubahan kualitas udara akan menyebabkan timbulnya beberapa dampak lanjutan, baik terhadap kesehatan manusia dan makhluk hidup lainnya, aspek estetika udara, keutuhan bangunan, dan lainnya. Dampak terhadap kesehatan manusia yang banyak terjadi adalah iritasi mata dan gangguan infeksi saluran pernafasan atas (ISPA), seperti hidung berair, radang batang tenggorokan, dan bronkitis [1]. Sehingga perlunya monitoring dan media informasi mengenai kualitas udara agar dapat dilakukan pengamatan tingkat pencemaran udara pada lingkungan masyarakat serta masyarakat dapat mengetahui informasi kualitas udara dengan mudah.

Informasi yang baik mengenai kualitas udara dan lingkungan merupakan kebutuhan masyarakat serta menjadi tolak ukur pengambilan keputusan dan tindakan penyelamatan lingkungan. Media dan teknik penyampaian kualitas udara yang kurang informatif menjadi pemicu rendahnya kesadaran masyarakat terhadap kondisi lingkungan. Oleh karena itu perlu dilakukan pemantauan untuk mengetahui kondisi serta kualitas udara secara real time, salah satunya membangun sistem kontrol dan monitoring Wireless Sensor Network (WSN).

Wireless Sensor Network adalah suatu infrastruktur jaringan wireless yang menggunakan sensor untuk memonitor fisik atau kondisi lingkungan sekitar. Desain WSN sangat tergantung pada aplikasi dan harus mempertimbangkan faktor-faktor seperti lingkungan, tujuan desain aplikasi, biaya, perangkat keras, dan kendala system. Pada WSN, terdapat node sensor tersebar di suatu lokasi. Tiap node sensor memiliki kemampuan mengumpulkan data dalam jumlah yang besar dari gejala yang timbul dari lingkungan sekitar. Sensor-sensor ini dilengkapi dengan antarmuka nirkabel yang dapat digunakan untuk berkomunikasi satu sama lain untuk membentuk jaringan [3][4]. Dengan menggunakan WSN bisa didapatkan data dari sensor secara real time kemudian data bisa ditampilkan dan dapat diakses dari halaman website.

Pada penelitian yang telah dilakukan oleh Aulia, et al [5] mengembangkan sistem informasi berbasis web dengan teknologi Wireless Sensor Network (WSN). Data lingkungan yg ditampilkan secara real time berupa karbon monoksida, nitrogen dioksida, partikel debu, suhu, kelembaban udara, intensitas cahaya dan kelembaban tanah. Namun data yang ditampilkan adalah data diinput secara manual oleh admin. Selanjutnya penelitian yang di lakukan oleh Yogha, et al [6] mengembangkan sistem untuk memonitoring dan otomatisasi suhu ruang dan kelembaban tanah dengan teknologi Wireless Sensor Network (WSN). Hasil dari penelitian ini didapatkan bahwa sistem mampu untuk memonitoring dan melakukan kontrol otomatis 
penurunan suhu dan mampu untuk meningkatkan kelembaban tanah. Data hasil monitoring dan otomatisasi dikirim ke web server sehingga memudahkan dalam pemantauan. Tetapi, berdasarkan pengujian jangkauan transmisi didapatkan bahwa jarak maksimum antara node dengan access point adalah 50 meter, dimana jika jarak lebih dari itu maka data tidak dapat terkirim ke web server.

Penelitian ini akan mengembangkan teknologi Wireless Sensor Network sebagai monitoring kualitas udara. Dimana perangkat tersebut akan diletakan pada beberapa lokasi lalu data kualitas dapat di tampilkan serta diakses pada web. Sehingga dapat dilakukan monitoring jarak jauh. Parameter yang diukur diantaranya carbon monoxide $(\mathrm{CO})$, carbon dioxide $(\mathrm{CO} 2)$, hydrocarbon $(\mathrm{HC})$, debu, suhu dan kelembaban udara. Kelebihan dari penelitian ini yaitu data real time dari sistem monitoring langsung dikirim secara wireless sehingga tidak perlu mengambil data secara manual, tidak ada batasan jangkauan selama masih terkoneksi dengan jaringan internet, memiliki standar-standar sehingga dapat mempersentasikan keadaan lokasi yang dimonitoring dan web ini memiliki fitur-fitur serta grafik yang ditampilkan secara lengkap dan informatif.

\section{Kajian Teori}

2.1 Aplikasi Sistem Wireless Sensor Network

Wireless Sensor Network atau jaringan sensor nirkabel merupakan media nirkabel untuk membentuk bidang sensor. WSN umunya terdiri dari kumpulan node sensor yang tersebar pada area tertentu yang digunakan untuk mengumpulkan data agar dapat memonitoring tentang suatu sistem atau lingkungan. Monitoring yang dilakukan seperti temperatur, kelembaban, tekanan, pergeseran dan lain-lain yang didukung secara otomatis dengan peralatan cerdas dalam mengelola sumber daya serta mengoptimalkan jadwal tugas secara real-time [7].

Wireless Sensor Network atau jaringan sensor nirkabel telah mendapatkan popularitas yang cukup besar karena fleksibilitasnya dalam memecahkan masalah di berbagai domain aplikasi dan berpotensi untuk mengubah hidup kita dengan berbagai cara. WSN telah berhasil diterapkan di berbagai domain aplikasi dan aspek kehidupan. Jaringan sensor saat ini (SNs) dapat memanfaatkan teknologi tidak tersedia 20 tahun yang lalu dan melakukan fungsi yang tidak bahkan bermimpi saat itu. Sensor, prosesor, dan perangkat komunikasi menjadi semakin kecil dan lebih murah [8].

Area monitoring: Di area monitoring, node sensor dikerahkan di atas wilayah dimana beberapa fenomena dipantau. Bila sensor mendeteksi kejadian yang dipantau (panas, tekanan dll), kejadian tersebut dilaporkan ke base station, yang kemudian akan diambil tindakan yang tepat.

Transportasi: Informasi lalu lintas real-time dikumpulkan oleh WSN untuk kemudian dikirimkan model transportasi dan driver peringatan kemacetan dan masalah lalu lintas. Informasi pelanggaran yang diterima dari transportasi juga termasuk WSN real time karena dari data yang dikumpulkan oleh cctv langsung dikirim ke server database [9].

Pengamatan Lingkungan: Jaringan sensor dapat digunakan untuk mengawasi perubahahan di lingkungan sekitar kita. Contohnya adalah deteksi polusi air sungai yang berlokasi dekat pabrik kimia. Node sensor dapat disebarkan secara acak ditempat yang tidak diketahui dan tidak bersahabat serta dapat mencari tahu lokasi polusi dengan tepat, sehingga dapat dilakukan tindakan pencegahan. Contoh lain pendeteksian polusi udara, monitoring habitat binatang serta monitoring salju atau lahan kritis untuk mencegah dan menghindari terjadinya longsoran.

Pelayanan Kesehatan: Sensor dapat digunakan pada aplikasi biomedikal untuk meningkatkan mutu pelayanan. Sensor juga dapat ditanamkan dalam tubuh untuk memonitor masalah kesehatan seperti kanker dan membantu pasien menjaga kesehatannya. [10]

\subsection{MySQL Sebagai Pengolah Database}

My Structured Query Language (MySQ) adalah sebuah program pembuat dan pengelola database atau yang sering disebut Database Management System (DBMS). sifat dari DBMS ini adalah open source. MySQL juga merupakan program pengakses database yang bersifat jaringan, sehingga dapat digunakan untuk aplikasi multi user (banyak pengguna). Kelebihan lain dari MySQL adalah menggunakan bahasa query (permintaan) standar SQL. SQL adalah suatu bahasa permintaan yang terstruktur, SQL telah distandarkan untuk semua program pengakses database [11].

MySQL sebenarnya merupakan turunan salah satu konsep utama dalam database sejak lama, yaitu SQL (Structured Query Language). SQL adalah sebuah konsep pengoperasian database, terutama untuk pemilihan atau seleksi dan pemasukan data, yang memungkinkan pengoperasian data dikerjakan dengan mudah secara otomatis. Keandalan suatu sistem database (DBMS) dapat diketahui dari cara kerja optimizer-nya dalam melakukan proses perintah-perintah SQL, yang dibuat oleh user maupun program-program aplikasinya [12].

\subsection{Penggunaan Hypertext Preprocessor (PHP) Untuk Perancangan Web}

PHP (Hypertext Preprocessor) merupakan bahasa pemrograman pada sisi server yang memperbolehkan programmer menyisipkan perintah - perintah perangkat lunak web server (Apache, IIS, atau apapun) akan dieksekusi sebelum perintah itu dikirim oleh halaman ke browser yang me-request-nya, contohnya adalah bagaimana memungkinkannya memasukkan tanggal sekarang pada sebuah halaman web setiap kali tampilan tanggal dibutuhkan. Sesuai dengan fungsinya yang berjalan di sisi server maka PHP adalah bahasa pemrograman yang digunakan untuk membangun teknologi web application. PHP telah menjadi bahasa scripting untuk keperluan umum yang pada awalnya hanya digunakan untuk pembangunan web yang menghasilkan halaman web dinamis. Untuk tujuan ini, kode PHP tertanam ke dalam dokumen sumber HTML dan diinterpretasikan oleh server web dengan modul PHP prosesor, yang menghasilkan dokumen halaman web.

Keseluruhan halaman-halaman web terdapat dalam sebuah domain yang mengandung informasi disebut Website. Sebuah website biasanya dibangun atas banyak halaman web yang saling berhubungan. Hubungan antara satu halaman web dengan halaman web lainnya disebut dengan hiperlink, 
sedangkan teks yang dijadikan media penghubung disebut hypertext. Website pada umumnya menggunakan database MySQL dan untuk merancang web salah satunya menggunakan bahasa pemograman PHP (Hypertext Preprocessor).

Sebagai bahasa pemrograman untuk tujuan umum, kode PHP diproses oleh aplikasi penerjemah dalam modus baris - baris perintah modus dan melakukan operasi yang diinginkan sesuai sistem operasi untuk menghasilkan keluaran program dichannel output standar. Hal ini juga dapat berfungsi sebagai aplikasi grafis. PHP tersedia sebagai prosesor untuk server web yang paling modern dan sebagai penerjemah mandiri pada sebagian besar system operasi dan komputer platform [7][13].

\section{Metodologi Penelitian}

Perancangan dalam penelitian ini dibagi menjadi dua bagian, yaitu perancangan perangkat keras (hardware) dan perancangan perangkat lunak (software). Perancangan perangkat keras (hardware) diawali dengan perancangan diagram blok sistem secara keseluruhan. Sedangkan perancangan perangkat lunak (software) diawali dengan flowcart sebagai alur kinerja. Blok diagram merupakan salah satu elemen terpenting dalam perancangan suatu alat, karena dari blok diagram rangkaian ini lah dapat diketahui alur kerja rangkaian keseluruhan. Sehingga keseluruhan blok diagram rangkaian tersebut akan menghasilkan suatu sistem yang dapat difungsikan.

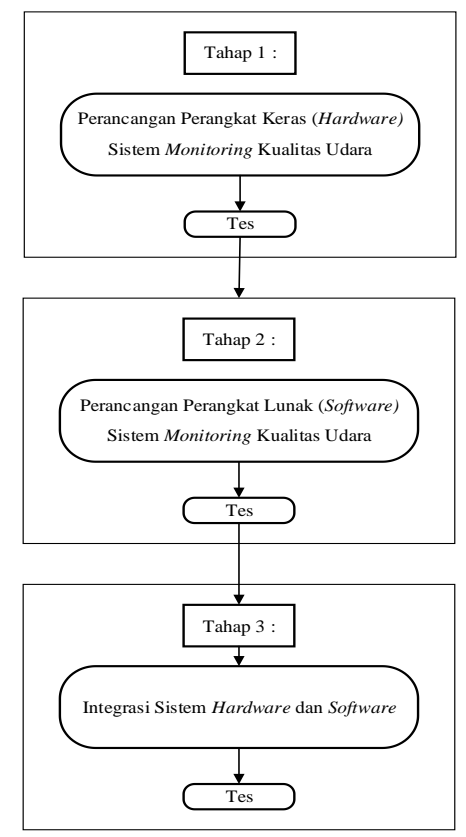

Gambar 1. Tahapan Penelitian Secara Keseluruhan

- Perancangan Perangkat Keras (Hardware) merupakan perancangan sistem monitoring kualitas berupa alat yang akan dibuat. Komponen yang digunakan harus memiliki karakteristik yang sesuai dengan kebutuhan alat.

- Perancangan Perangkat Lunak (Software) merupakan perancangan untuk memberi perintah dan mengirimkan hasil pembacaan sensorsensor dari program putty ke server. Setelah itu web akan menampilkan data yang tersimpan pada server dengan menggunakan teknologi Wireless Sensor Network.

- Integrasi Sistem Hardware dan Software merupakan proses untuk menggabungkan fungsi perangkat keras (Hardware) dan fungsi perangkat lunak (Software). Setelah itu dilakukan proses pengujian perangkat keras (Hardware) dan perangkat lunak (Software).

\section{Hasil Uji Coba Dan Pembahasan}

4.1 Hasil Perancangan Perangkat Keras (Hardware)

Perancangan sistem monitoring kualitas udara menggunakan teknologi Wireless Sensor Network yang terdiri dari node 1, node 2 dan node 3. Sistem pemantauan kualitas udara ini, di rancang menggunakan Raspberry PI 3 model B sebagai mikroprosessor. Sumber daya yang digunakan pada alat ini yaitu baterai lippo 12V. Alat ini juga menggunakan 5 sensor kualitas udara yaitu sensor yaitu sensor TGS 2442 sebagai sensor CO, sensor MG811 sebagai sensor CO2, sensor TGS 2611 sebagai sensor HC, sensor SHARP GP2Y1010 sebagai sensor debu dan sensor DHT11 sebagai sensor suhu dan kelembapan. Dan modul ADC atau Analog to Digital Converter yakni ADS-1115 sebagai konverter nilai pembacaan sensor agar dapat di proses oleh Raspberry PI dan modul GPS Neo-6M sebagai pemberi informasi tentang titik koordianat masing-masing node berupa latitude dan longtitude. Agar Raspberry PI dapat mengirimkan data pembacaan sensor ke database dan dikirim secara real time, digunakan modem wifi sebagai penyedia layanan internet.

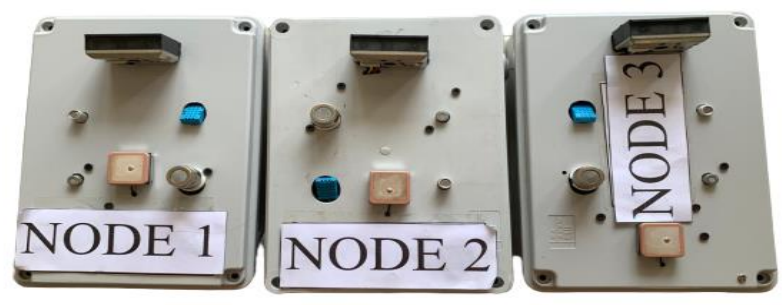

Gambar 2. Perangkat Keras (Hardware) 
Perangkat keras (hardware) pada gambar 4.1 dapat terlihat masing-masing sensor diletakkan pada kotak (box). Masing-masing node diletakkan pada kotak (box) untuk menghindari resiko kerusakan, sehingga perangkat keras (hardware) tetap terjaga serta dapat berfungsi dengan baik.

4.2 Hasil Pengujian Pengiriman Data dari Node ke Server

Pengujian pengiriman data dari node 1 , node 2 dan node 3 yang telah dilakukan, masing-masing node tersebut telah berhasil menambahkan data terlihat dari program putty gambar 4.2 sebagai penampil nilai sensor pada alat, lalu nilai data sensor dikirim ke database.

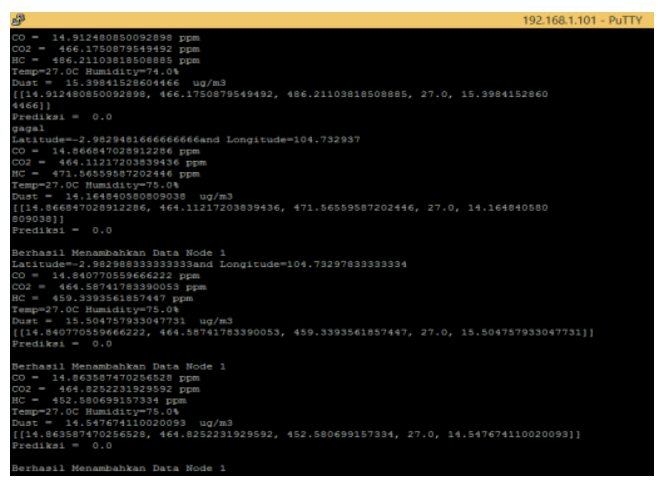

Gambar 3. Hasil Program Putty

Setelah dilakukan pengujian node 1 , node 2 dan node 3 dapat bekerja dengan baik dan mengirimkan data pembacaan sensor ke database. Database berhasil menerima data dari program putty sehingga data tersebut dapat terlihat pada tampilan database. Hasil nilai data pada database sesuai nilai data dari program putty.

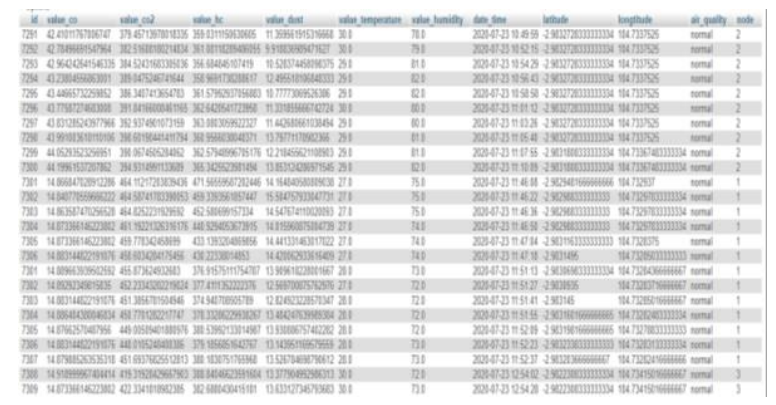

Gambar 4. Hasil Database

Dari hasil pengujian yang dilakukan terlihat bahwa node 1, node 2 dan node 3 dapat mengirim data ke server dan data sensor masuk ke sistem database terlihat pada gambar 4.3, data masuk database berkisar 14-30 detik tergantung kecepatan jaringan internet. Data yang tersimpan pada database terdiri dari $\mathrm{CO}, \mathrm{CO} 2, \mathrm{HC}$, dust, temperature, humidity, date time, latitude, longtitude, air quality dan node. Setelah dilakukan pengujian sistem dapat bekerja degan baik dan dapat menampilkan informasi pada 3 lokasi di Politeknik Negeri Sriwijaya.

\subsubsection{Hasil Pengujian Data dari Node 1}

Pengujian node 1 yaitu dilakukan di lapangan parkir Gedung KPA Politeknik Negeri Sriwijaya. Node 1 berhasil menyimpan data kualitas udara pada database sebanyak 2049 data. Gambar 4.4 merupakan lokasi penempatan node 1. 


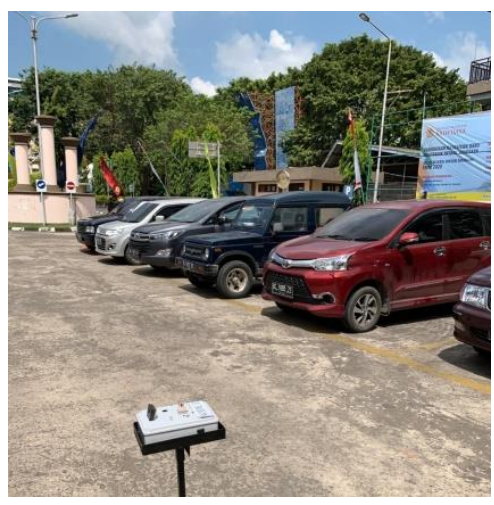

Gambar 5. Pengujian Node 1 di Lapangan Parkir Gedung KPA

Tabel 1: Data Node 1 Kualitas Udara di Lapangan Parkir Geduang KPA

\begin{tabular}{|c|c|c|c|c|c|c|c|c|c|c|c|}
\hline No & $\begin{array}{c}\mathrm{CO} \\
(\mathrm{ppm})\end{array}$ & $\begin{array}{c}\mathrm{CO}_{2} \\
(\mathrm{ppm}) \\
\end{array}$ & $\begin{array}{c}\text { HC } \\
(\mathrm{ppm})\end{array}$ & $\begin{array}{c}\text { Dust } \\
\left(\mu \mathrm{g} / \mathbf{m}^{3}\right)\end{array}$ & $\begin{array}{c}\text { Temperature } \\
\left({ }^{\circ} \mathrm{C}\right)\end{array}$ & $\begin{array}{c}\text { Humidity } \\
(\%)\end{array}$ & $\begin{array}{l}\text { Date } \\
\text { Time } \\
\end{array}$ & Latitude & Longtitude & $\begin{array}{c}\text { Air } \\
\text { Quality }\end{array}$ & Node \\
\hline 1. & $\begin{array}{c}41.513 \\
739039 \\
73402\end{array}$ & $\begin{array}{l}498.26 \\
665474 \\
342786\end{array}$ & $\begin{array}{l}438.65 \\
358467 \\
792856\end{array}$ & $\begin{array}{c}27.94684 \\
7632407 \\
02\end{array}$ & 31.0 & 70.0 & $\begin{array}{c}2020-07- \\
22 \\
10: 25: 13\end{array}$ & $\begin{array}{c}- \\
2.983296 \\
667\end{array}$ & $\begin{array}{c}104.732867 \\
93\end{array}$ & normal & 1 \\
\hline 2. & $\begin{array}{c}42.302 \\
552234 \\
42746\end{array}$ & $\begin{array}{l}545.50 \\
348564 \\
250726\end{array}$ & $\begin{array}{c}438.04 \\
753192 \\
6098\end{array}$ & $\begin{array}{c}27.71289 \\
3809000 \\
263 \\
\end{array}$ & 31.0 & 70.0 & $\begin{array}{c}2020-07- \\
22 \\
10: 25: 27\end{array}$ & $\begin{array}{c}- \\
2.983296 \\
667\end{array}$ & $\begin{array}{c}104.732867 \\
93\end{array}$ & normal & 1 \\
\hline 3. & $\begin{array}{c}43.052 \\
250725 \\
2518\end{array}$ & $\begin{array}{l}608.00 \\
110948 \\
849635\end{array}$ & $\begin{array}{c}438.74 \\
023206 \\
38718\end{array}$ & $\begin{array}{c}28.60617 \\
2043826 \\
064\end{array}$ & 31.0 & 70.0 & $\begin{array}{c}2020-07- \\
22 \\
10: 25: 40\end{array}$ & $\begin{array}{c}- \\
2.983296 \\
667\end{array}$ & $\begin{array}{c}104.732867 \\
93\end{array}$ & moderate & 1 \\
\hline 4. & $\begin{array}{l}43.717 \\
200691 \\
026434\end{array}$ & $\begin{array}{c}634.25 \\
508100 \\
855114\end{array}$ & $\begin{array}{c}438.13 \\
405959 \\
82427\end{array}$ & $\begin{array}{c}28.39348 \\
6749819 \\
92\end{array}$ & 31.0 & 70.0 & $\begin{array}{c}2020-07- \\
22 \\
10: 25: 54\end{array}$ & $\begin{array}{c}- \\
2.983296 \\
667\end{array}$ & $\begin{array}{c}104.732867 \\
93\end{array}$ & moderate & 1 \\
\hline 5. & $\begin{array}{c}44.398 \\
448450 \\
07986\end{array}$ & $\begin{array}{l}649.36 \\
841543 \\
908395\end{array}$ & $\begin{array}{c}438.04 \\
753192 \\
6098\end{array}$ & $\begin{array}{c}28.64870 \\
9102627 \\
29\end{array}$ & 31.0 & 70.0 & $\begin{array}{c}2020-07- \\
22 \\
10: 26: 07\end{array}$ & $\begin{array}{c}- \\
2.983296 \\
667\end{array}$ & $\begin{array}{c}104.732867 \\
93\end{array}$ & moderate & 1 \\
\hline
\end{tabular}

Pada tabel 1 merupakan data hasil pembacaan sensor node 1 yang dilakukan dan berhasil disimpan pada database. Pada data testing ke-1 hasil pembacaan node 1 pada database $\mathrm{CO}$ sebesar 41.51373903973402 ppm, $\mathrm{CO}_{2}$ sebesar 498.26665474342786 ppm, $\mathrm{HC}$ sebesar 438.65358467792856 ppm, dust sebesar 27.94684763240702 $\mu \mathrm{g} / \mathrm{m}^{3}$, temperature sebesar 31.0 ${ }^{\circ} \mathrm{C}$, humidity sebesar 70.0\%, waktu pengujian 2020-07-22 10:25:13, latitude -2.983296667, longtitude 104.73286793, air quality normal dan node yaitu 1. Hasil data testing ke-3 didapatlah hasil pembacaan kualitas udara berubah terklasifikasi moderate. Untuk data hasil node 1 pada tabel 4.1 data CO semakin meningkat tetapi peningkatnya nilai hasil pengujian hanya sedikit selisihnya, data $\mathrm{CO} 2$ nilainya naik turun tetapi data testing terakhir meningkat jauh lebih dari data testing awal, data HC juga mengalami naik turun tetapi nilai data terakhir melampaui nilai data awal, data dust nilainya masih naik turun tetapi masih dalam range yang hampir besar, data temperature yaitu $31.0{ }^{\circ} \mathrm{C}$ dan humidity kisaran $71 \%$. Dan hasil kualitas udara pada lokasi tersebut terklasifiikasi dominan moderate dan normal. Hal ini dikarenakan lokasi lapangan parkir Gedung KPA merupakan tempat jalan keluar masuk Kampus Politeknik Negeri Sriwijaya. Jadi terdapat banyaknya aktivitas dan kendaraan yang lalu lalang pada lokasi tersebut, sehingga polusi udara dari kendaraan menyebabkan kualitas udara tercemari.

\subsubsection{Hasil Pengujian Data dari Node 2}

Pada pengujian node 2 yaitu dilakukan di lapangan parkir Teknik Elektro. Pada gambar dibawah ini menunjukan penempatan dari pengujian node 2. Node 2 berhasil menyimpan data kualitas udara pada database sebanyak 2062 data. Pada gambar 4.5 lokasi penempatan node sensor 2.

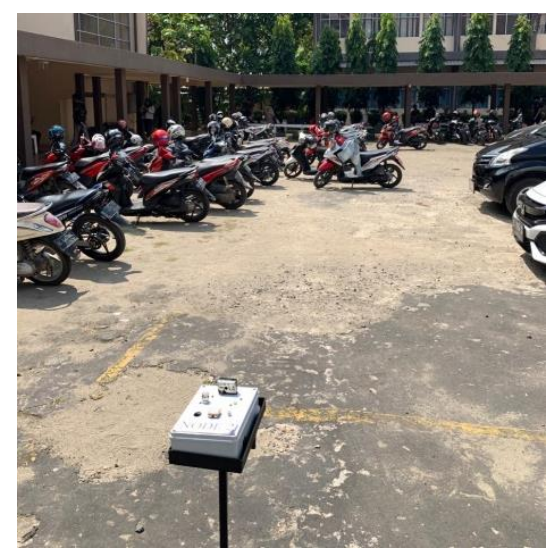

Gambar 6. Pengujian Node 2 di Lapangan Parkir Teknik Elektro

Tabel 2: Data Node 2 Kualitas Udara di Lapangan Parkir Teknik Elektro 


\begin{tabular}{|c|c|c|c|c|c|c|c|c|c|c|c|}
\hline No & $\begin{array}{c}\mathrm{CO} \\
(\mathrm{ppm})\end{array}$ & $\begin{array}{c}\mathrm{CO}_{2} \\
(\mathrm{ppm})\end{array}$ & $\begin{array}{c}\mathbf{H C} \\
(\mathbf{p p m})\end{array}$ & $\begin{array}{c}\text { Dust } \\
\left(\mu \mathrm{g} / \mathrm{m}^{3}\right)\end{array}$ & $\begin{array}{c}\text { Temperature } \\
\left({ }^{\circ} \mathrm{C}\right)\end{array}$ & $\begin{array}{c}\text { Humidity } \\
(\%)\end{array}$ & $\begin{array}{l}\text { Date } \\
\text { Time }\end{array}$ & Latitude & Longtitude & $\begin{array}{c}\text { Air } \\
\text { Quality }\end{array}$ & Node \\
\hline 1. & $\begin{array}{c}33.162 \\
749763 \\
682\end{array}$ & $\begin{array}{c}605.03 \\
105394 \\
170944\end{array}$ & $\begin{array}{l}387.14 \\
846281 \\
049387\end{array}$ & $\begin{array}{c}25.15727 \\
3705140 \\
327\end{array}$ & 31.0 & 71.0 & $\begin{array}{c}2020-07- \\
22 \\
10: 27: 24\end{array}$ & $\begin{array}{c}- \\
2.983395 \\
937934\end{array}$ & $\begin{array}{c}104.733816 \\
897\end{array}$ & moderate & 2 \\
\hline 2. & $\begin{array}{c}33.394 \\
178428 \\
240814\end{array}$ & $\begin{array}{c}614.12 \\
460241 \\
64977\end{array}$ & $\begin{array}{c}385.68 \\
169470 \\
800035\end{array}$ & $\begin{array}{c}23.85508 \\
0022165\end{array}$ & 31.0 & 71.0 & $\begin{array}{c}2020-07- \\
22 \\
10: 27: 39\end{array}$ & $\begin{array}{c}- \\
2.983395 \\
937934\end{array}$ & $\begin{array}{c}104.733816 \\
897\end{array}$ & normal & 2 \\
\hline 3. & $\begin{array}{c}33.866 \\
814433 \\
32573\end{array}$ & $\begin{array}{l}635.46 \\
422511 \\
786847\end{array}$ & $\begin{array}{c}385.61 \\
515562 \\
774844\end{array}$ & $\begin{array}{c}25.82222 \\
3670914 \\
962\end{array}$ & 31.0 & 70.0 & $\begin{array}{c}2020-07- \\
22 \\
10: 27: 53\end{array}$ & $\begin{array}{c}- \\
2.983395 \\
937934\end{array}$ & $\begin{array}{c}104.733816 \\
897\end{array}$ & normal & 2 \\
\hline 4. & $\begin{array}{c}34.241 \\
663678 \\
7379\end{array}$ & $\begin{array}{c}626.68 \\
046349 \\
18889\end{array}$ & $\begin{array}{c}385.88 \\
138084 \\
581783\end{array}$ & $\begin{array}{c}26.32093 \\
6145245 \\
938\end{array}$ & 32.0 & 70.0 & $\begin{array}{c}2020-07- \\
22 \\
10: 28: 07\end{array}$ & $\begin{array}{c}- \\
2.983395 \\
937934\end{array}$ & $\begin{array}{c}104.733816 \\
897\end{array}$ & normal & 2 \\
\hline 5. & $\begin{array}{c}34.456 \\
794550 \\
017925\end{array}$ & $\begin{array}{l}628.16 \\
635932 \\
700086\end{array}$ & $\begin{array}{c}387.95 \\
086792 \\
731814\end{array}$ & $\begin{array}{c}26.01616 \\
7410932 \\
56\end{array}$ & 31.0 & 70.0 & $\begin{array}{c}2020-07- \\
22 \\
10: 28: 21\end{array}$ & $\begin{array}{c}- \\
2.983395 \\
937934\end{array}$ & $\begin{array}{c}104.733816 \\
897\end{array}$ & moderate & 2 \\
\hline
\end{tabular}

Data hasil pembacaan sensor node 2 pada tabel 2 merupakan data yang dilakukan dan berhasil disimpan. Hasil pembacaan node 2 pada data testing ke-5 hasil pembacaan node 1 pada database $\mathrm{CO}$ sebesar $34.456794550017925 \mathrm{ppm}, \mathrm{CO}_{2}$ sebesar 628.16635932700086 ppm, $\mathrm{HC}$ sebesar $387.95086792731814 \mathrm{ppm}$, dust sebesar $26.01616741093256 \mu \mathrm{g} / \mathrm{m}^{3}$, temperature $31.0{ }^{\circ} \mathrm{C}$, humidity sebesar $70.0 \%$, waktu pengujian $2020-07-22$ 10:28:21, latitude -2.983395937934, longtitude 104.733816897, air quality moderate dan node yaitu 2. Dan masih sama dengan node 1 , node 2 juga terdapat hasil data pembacaan sensor yang air quality-nya moderate. Untuk data hasil node 2 perubahan $\mathrm{CO}_{1} \mathrm{CO}_{2}, \mathrm{HC}$ dan dust ini tidak lebih besar dari node 1 dikarenakan kendaraan pada lapangan parkir Teknik Elektro tidak terlalu banyak dan sedikitnya aktivitas pada saat itu. Namun untuk temperature dan humidity terdapat data lebih tinggi daripada node 1 karena perubahan yang mempengaruhi temperature yaitu tinggi rendahnya intensitas cahaya yang menyinari perangkat keras (hardware) tersebut dan perubahan yang mempengaruhi humidity yaitu pergerakan angin. Semakin tinggi kecepatan angin maka akan mempercepat pengangkatan uap air yang mengepul ke udara. Dan hasil kualitas udara pada lokasi tersebut terklasifikasi normal dan moderate. Hal ini dikarenakan lapangan parkir Teknik Elektro juga digunakan untuk berbagai jurusan sehingga banyaknya kendaraan serta banyaknya aktivitas di lokasi tersebut.

\subsubsection{Hasil Pengujian Data dari Node 3}

Pada pengujian node 3 yaitu dilakukan di lapangan parkir Manajemen Informatika. Node 3 berhasil menyimpan data kualitas udara pada database sebanyak 2091 data. Gambar 4.10 merupakan lokasi pengujian Node 3.

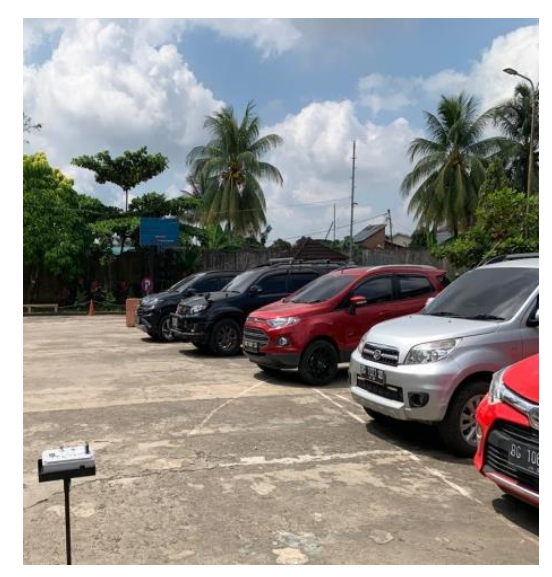

Gambar 7. Pengujian Node 3 di Lapangan Parkir Manajemen Informatika

Tabel 3: Data Node 3 Kualitas Udara di Lapangan Parkir Teknik Elektro

\begin{tabular}{|c|c|c|c|c|c|c|c|c|c|c|c|}
\hline No & $\begin{array}{c}\text { CO } \\
\text { (ppm) }\end{array}$ & $\begin{array}{c}\mathrm{CO}_{2} \\
(\mathrm{ppm})\end{array}$ & $\begin{array}{c}\text { HC } \\
(\mathbf{p p m})\end{array}$ & $\begin{array}{c}\text { Dust } \\
\left(\mu \mathrm{g} / \mathrm{m}^{3}\right)\end{array}$ & $\begin{array}{c}\text { Temperature } \\
\left({ }^{\circ} \mathrm{C}\right)\end{array}$ & $\begin{array}{c}\text { Humidity } \\
(\%)\end{array}$ & $\begin{array}{l}\text { Date } \\
\text { Time }\end{array}$ & Latitude & Longtitude & $\begin{array}{c}\text { Air } \\
\text { Quality }\end{array}$ & Node \\
\hline 1. & $\begin{array}{l}35.310 \\
798917 \\
826524\end{array}$ & $\begin{array}{l}365.78 \\
293175 \\
268186\end{array}$ & $\begin{array}{l}319.57 \\
237834 \\
947455\end{array}$ & $\begin{array}{c}17.07862 \\
9108693 \\
182\end{array}$ & 31.0 & 73.0 & $\begin{array}{c}2020-07- \\
22 \\
10: 25: 15\end{array}$ & $\begin{array}{c}- \\
2.982352 \\
953334\end{array}$ & $\begin{array}{c}104.734392 \\
33736\end{array}$ & normal & 3 \\
\hline 2. & $\begin{array}{c}37.093 \\
777502 \\
52616 \\
\end{array}$ & $\begin{array}{l}364.50 \\
400884 \\
908044 \\
\end{array}$ & $\begin{array}{l}318.02 \\
036119 \\
767195 \\
\end{array}$ & $\begin{array}{c}17.61034 \\
2343708 \\
53 \\
\end{array}$ & 31.0 & 73.0 & $\begin{array}{c}2020-07- \\
22 \\
10: 25: 29 \\
\end{array}$ & $\begin{array}{c}- \\
2.982352 \\
953334 \\
\end{array}$ & $\begin{array}{c}104.734392 \\
337365\end{array}$ & normal & 3 \\
\hline 3. & 36.314 & 373.73 & 321.71 & 16.73833 & 31.0 & 73.0 & 2020-07- & - & 104.734392 & normal & 3 \\
\hline
\end{tabular}




\begin{tabular}{|c|c|c|c|c|c|c|c|c|c|c|c|}
\hline & $\begin{array}{l}742983 \\
799995\end{array}$ & $\begin{array}{l}821290 \\
789647\end{array}$ & $\begin{array}{c}877675 \\
84143\end{array}$ & $\begin{array}{c}2638283 \\
357\end{array}$ & & & $\begin{array}{c}22 \\
10: 25: 42\end{array}$ & $\begin{array}{c}2.982352 \\
953334\end{array}$ & 337365 & & \\
\hline 4. & $\begin{array}{l}36.546 \\
171648 \\
358815\end{array}$ & $\begin{array}{c}365.23 \\
427338 \\
59769\end{array}$ & $\begin{array}{l}321.26 \\
227872 \\
195943\end{array}$ & $\begin{array}{c}17.56780 \\
5284907 \\
305\end{array}$ & 31.0 & 73.0 & $\begin{array}{c}2020-07- \\
22 \\
10: 25: 56\end{array}$ & $\begin{array}{c}- \\
2.982352 \\
953334\end{array}$ & $\begin{array}{c}104.734392 \\
337365\end{array}$ & normal & 3 \\
\hline 5. & $\begin{array}{c}36.239 \\
773134 \\
71756\end{array}$ & $\begin{array}{c}364.13 \\
942430 \\
867166\end{array}$ & $\begin{array}{c}321.71 \\
877675 \\
84143\end{array}$ & $\begin{array}{c}18.26966 \\
6755127 \\
57\end{array}$ & 31.0 & 73.0 & $\begin{array}{c}2020-07- \\
22 \\
10: 26: 10\end{array}$ & $\begin{array}{c}- \\
2.982352 \\
953334\end{array}$ & $\begin{array}{c}104.734392 \\
337365\end{array}$ & normal & 3 \\
\hline
\end{tabular}

Dapat terlihat pada tabel 3 merupakan data hasil pembacaan sensor node 3 yang dilakukan dan berhasil disimpan pada database. Hasil pembacaan node 3 pada database CO sebesar 35.310798917826524 ppm, CO2 365.78293175268186 ppm, HC 319.57237834947455 ppm, 17.078629108693182, temperature $31.0{ }^{\circ} \mathrm{C}$, humidity 73.0\%, waktu pengujian 2020-07-22 10:25:15, latitude -2.982352953334, longtitude 104.73439233736, air quality normal dan node yaitu 3. Untuk data hasil node 3 perubahan CO lebih kecil dari node 1 dan lebih besar dari node 2 tetapi masih dalam range yang hampir sama besar, CO2 juga nilainya tidak melebihi node 1 serta lebih besar dari node 2 . Namun nilai $\mathrm{HC}$ paling kecil daripada node 1 dan node 2 karena lapangan parkir Manajemen Informatika pada saat itu kendaraan yang parkir hanya sedikit. Nilai HC yang paling tinggi yaitu node 1 . Tingginya nilai HC menunjukkan adanya gas buang pada kendaraan dimana proses pembakarannya yang tidak sempurna. Lalu nilai kadar dust juga paling kecil diantara node 1 dan node 2 . Untuk temperature nilai sama seperti node 1 serta tidak lebih tinggi dari node 2 dan humidity lebih rendah daripada node 1 dan node 2 karena cuaca sangat mempengaruhi untuk perubahan itu. Semakin tinggi temperature maka nilai humidity semakin lebih kecil. Dan hasil kualitas udara pada lokasi tersebut terklasifikasi normal. Hal ini dikarenakan pada saat pengambilan data sedikitnya aktivitas serta sedikitnya kendaraan yang lalu lalang pada lokasi tersebut. Kualitas udara terklasifikasi normal yang berarti udara dalam keadaan yang baik dan tidak tercemari.

\subsection{Hasil Pengujian Web}

Pengujian ini dilakukan dengan cara mengakses web https://adevpolsri.online/ untuk monitoring data-data kualitas udara dimanapun $u s e r$ berada selama terkoneksi dengan internet baik itu melalui laptop, PC ataupun perangkat ponsel. Hasil monitoring ini untuk mengetahui hasil dari perancangan web yang menampilkan 4 halaman yang terdiri dari halaman menu, halaman dashboard, halaman history dan halaman grafik. Sistem kinerja web ini berhasil merancang web sebagai sistem monitoring kualitas udara yang terintegrasi dengan perangkat Wireless Sensor Network. Dan hasil monitoring menggunakan web ini mendapatkan hasil yang sama seperti hasil pengujian dari perangkat keras (hardware) Wireless Sensor Network. Data kualitas udara berdasarkan pembacaan sensor yang tersimpan pada database lalu ditampilkan pada web. Sehingga web dapat memudahkan serta memberi informasi kualitas udara secara efektif.

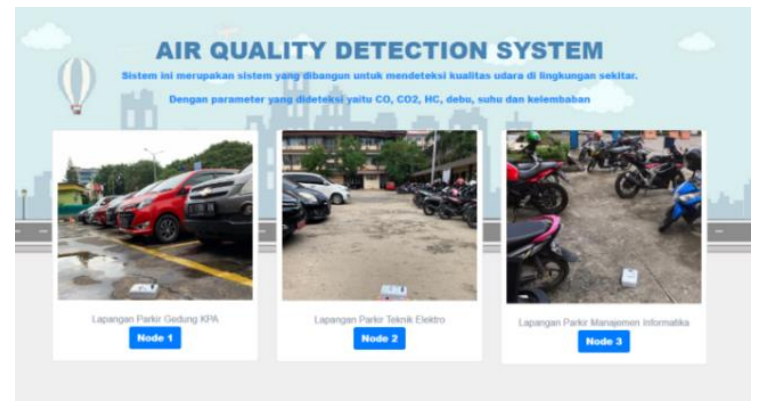

(a)

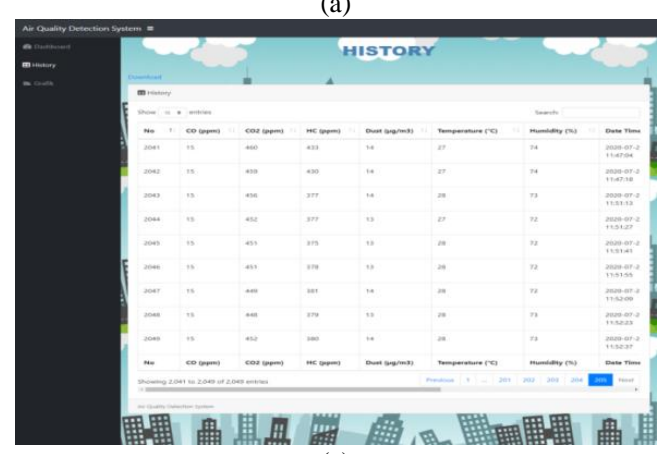

(c)

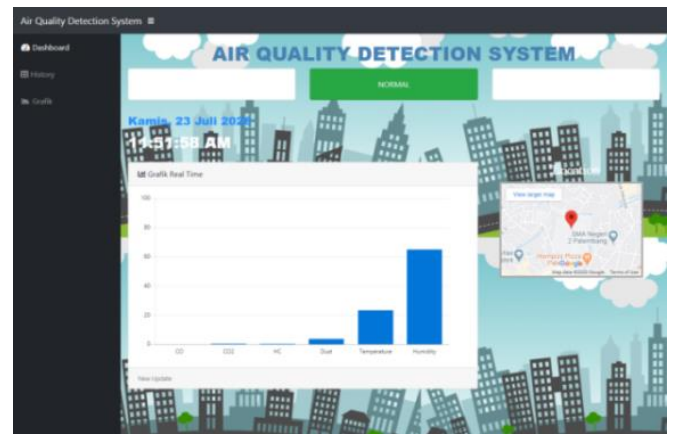

(b)

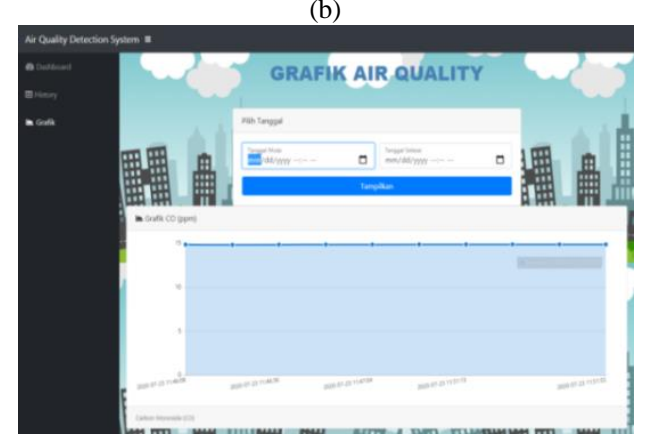

(d)

Gambar 4.4 (a) Halaman Menu, (b) Halaman Dashboard, (c) Halaman History, (d) Halaman Grafik

\section{Kesimpulan}

Berdasarkan hasil pengujian yang telah dilakukan, maka dapat disimpulkan perangkat keras (hardware) berhasil mengirim data pembacaan sensor pada database dengan selang waktu berkisar 13-30 detik dan web sebagai sistem monitoring kualitas udara berhasil menampilkan informasi mengenai kualitas udara karena perangkat keras (hardware) dan perangkat lunak (software) sudah terintegrasi dengan baik. Berdasarkan kesimpulan yang didapatkan, maka penulis merekomendasikan berupa saran penggunaan alat sebaiknya diimplementasikan pada area dengan tingkat polusi yang lebih tinggi dan dianggap perlu untuk dilakukan pengamatan untuk kedepannya.

\section{Daftar Pustaka}

[1] R. Satra and A. Rachman, "Pengembangan Sistem Monitoring Pencemaran Udara Berbasis Protokol ZIGBEE dengan Sensor CO,” Ilk. J. Ilm., vol. 8 No. 1, pp. 17. 2016. 
[2] Widianjaya, Adhe. dkk, “Green Map” Sistem Monitoring Dan Peta Visualisasi Distribusi Kualitas Udara Berbasis Web,” Jurnal Teknik Informatika dan Komputer., pp. 1. 2014

[3] J. Yick, B. Mukherjee, and D. Ghosal, “Wireless sensor network survey,” Comput. Networks, 2008, doi: 10.1016/j.comnet.2008.04.002.

[4] Firnandus, M. N \& Yasri, I, “Aspek Penerapan Wireless Sensor Network Untuk Mendeteksi Pencemaran Udara Akibat Kabut Asap Kebakaran Hutan," Jom FTEKNIK., vol 3 No. 2, pp. 1. 2016.

[5] Ramadhan, M. A., Nurhayati, D. O \& Widianto, D. O, “Rancang Bangun Sistem Informasi Kampus Hijau Berbasis Web Pada JSN (Jaringan Sensor Nirkabel)”. Jurnal Teknologi dan Sistem Komputer, 4 (2), pp. 361-368. 2016.

[6] Adnantha, A. Y \& Kusuma, A. W, “Implementasi Wireless Sensor Network untuk Otomatisasi Suhu Ruang dan Kelembaban Tanah pada Greenhouse Berbasis Web Server”. Jurnal Teknik Informatika, vol 3 No. 1, pp. 14-21. 2018.

[7] Pujiana, I. A. dkk, “Perancangan Wireless Sensor Network Dalam Sistem Monitoring Lingkungan,” Prosiding Annual Research., vol 3 No. 1, pp. 199. 2017.

[8] Nyayu Latifah Husni, Ade Silvia, and Siti Nurmaini.,"New Challenges In Air Quality Sensing Using Robotic Sensor Network,".International Conference on Innovations in Engineering and Technology (ICIET'2013), Bangkok (Thailand), 2013.

[9] Tarmidi, Ahmad Taqwa, Ade Silvia H, "Penerapan Wireless Sensor Network Sebagai Monitoring Lingkungan Berbasis Android". Jurnal Inovasi dan Aplikasi Teknologi., pp. 225-226. 2019.

[10] Mige, Samuel, E. G. dkk, “Testbed Performa Node Sensor, Motes Dan Gateway Crossbow Dengan Variasi Penempatan Posisi Sensor Pada Desain Smart House Berbasis WSN”. Jurnal SPEKTRO., vol. 2 No. 1, pp. 44. 2019.

[11] Fahrudin, A., Purnama, E. B \& Riasti, K. B, "Pembangunan Sistem Informasi Layanan Haji Berbasis Web Pada Kelompok Bimbingan Ibadah Haji Ar Rohman Mabrur Kudus”. Jurnal Teknologi Informatika Universitas Surakarta, vol.3 No. 1, pp. 36.2011.

[12] Y. L. Prihartanto, “ ，” J. Speed-Sentra Penelit. Eng. dan Edukasi., vol. 3 No.3, pp. 55. 2011.

[13] Februariyanti, Herny \& Zuliarso, Eri, “Rancang Bangun Sistem Perpustakaan untuk Jurnal Elektronik,” J. Teknol. Inf. Din., vol. 17 No. 2, pp. 128. 2012. 